\title{
Weak Convergence Theorems on the Split Common Fixed Point Problem for Demicontractive Continuous Mappings
}

\author{
Huanhuan Cui ${ }^{D},{ }^{1}$ Luchuan Ceng, ${ }^{1}$ and Fenghui Wang ${ }^{2}$ \\ ${ }^{1}$ Department of Mathematics, Shanghai Normal University, Shanghai 200234, China \\ ${ }^{2}$ Department of Mathematics, Luoyang Normal University, Luoyang 471022, China \\ Correspondence should be addressed to Huanhuan Cui; hhcui@live.cn
}

Received 14 January 2018; Accepted 1 April 2018; Published 7 May 2018

Academic Editor: Thomas Schuster

Copyright (c) 2018 Huanhuan Cui et al. This is an open access article distributed under the Creative Commons Attribution License, which permits unrestricted use, distribution, and reproduction in any medium, provided the original work is properly cited.

\begin{abstract}
We are concerned with the split common fixed point problem in Hilbert spaces. We propose a new method for solving this problem and establish a weak convergence theorem whenever the involved mappings are demicontractive and Lipschitz continuous. As an application, we also obtain a new method for solving the split equality problem in Hilbert spaces.
\end{abstract}

\section{Introduction}

The split common fixed point problem (SCFP) is an inverse problem that aims to find an element in a fixed point set such that its image under a linear transformation belongs to another fixed point set. More specifically, given two Hilbert spaces $H_{1}$ and $H_{2}$, the SCFP consists in finding $x \in H_{1}$ such that

$$
\begin{array}{r}
x \in F(U), \\
A x \in F(T),
\end{array}
$$

where $A: H_{1} \rightarrow H_{2}$ is a bounded linear mapping and $F(U)$ and $F(T)$ are, respectively, the fixed point sets of nonlinear mappings $U: H_{1} \rightarrow H_{1}$ and $T: H_{2} \rightarrow H_{2}$. Particularly, if $U$ and $T$ are both metric projections, the SCFP is reduced to the well-known split feasibility problem (SFP). Actually, the SFP can be formulated as the problem of finding a point $x \in H_{1}$ such that

$$
\begin{array}{r}
x \in C, \\
A x \in Q,
\end{array}
$$

where $C \subseteq H_{1}$ and $Q \subseteq H_{2}$ are nonempty closed convex sets, and mapping $A$ is as above. These two problems have been extensively investigated since they play an important role in various areas including signal processing and image reconstruction [1-5].
We assume throughout the paper that problem (P1) is consistent, which means that its solution set, denoted by $S$, is nonempty. Censor and Segal [6] studied the SCFP when $U$ and $T$ are firmly quasi-nonexpansive mappings, and proposed the following method:

$$
x_{n+1}=U\left[x_{n}-\tau_{n} A^{*}(I-T) A x_{n}\right],
$$

where $\tau_{n}$ is a properly chosen stepsize. It is shown that if $\tau_{n}$ is chosen in $\left(0,2 /\|A\|^{2}\right)$, then the sequence generated by method (2) converges weakly to a solution of problem (P1). Subsequently, this result was extended to quasi-nonexpansive operators [7], demicontractive operators [8, 9], two groups of finitely many firmly quasi-nonexpansive mappings [10, 11], and the more general common null point problem [12]. Also, some variants of method (2) have been considered in [13-16].

Since the choice of the stepsize is related to $\|A\|$, thus, to implement method (3), one has to compute (or at least estimate) the norm $\|A\|$, which is generally not easy in practice. A way to avoid this is to adopt variable stepsize which ultimately has no relation with $\|A\|[8,10,17-19]$. Wang [18] recently proposed a new method for solving the SCFP:

$$
x_{n+1}=x_{n}-\rho_{n}\left[(I-U) x_{n}+A^{*}(I-T) A x_{n}\right] \text {, }
$$

where $\left\{\rho_{n}\right\} \subset(0, \infty)$ is chosen such that

$$
\rho_{n}=\frac{\left\|(I-U) x_{n}\right\|^{2}+\left\|(I-T) A x_{n}\right\|^{2}}{\left\|(I-U) x_{n}+A^{*}(I-T) A x_{n}\right\|^{2}} .
$$


Wang proved that if mappings $U$ and $T$ are firmly quasinonexpansive, then the sequence $\left\{x_{n}\right\}$ generated by (3)(4) converges weakly to a solution of problem (P1). Wang and $\mathrm{Xu}[19]$ recently proposed another choice of the stepsize:

$$
\rho_{n}=\frac{\tau_{n}}{\left\|(I-U) x_{n}+A^{*}(I-T) A x_{n}\right\|},
$$

where $\left\{\tau_{n}\right\} \subset(0, \infty)$ is chosen such that

$$
\begin{aligned}
& \sum_{n=0}^{\infty} \tau_{n}=\infty \\
& \sum_{n=0}^{\infty} \tau_{n}^{2}<\infty
\end{aligned}
$$

They proved that if mappings $U$ and $T$ are nonexpansive, then the sequence $\left\{x_{n}\right\}$ generated by (3) and (5)-(6) converges weakly to a solution of problem (P1). It is clear that these choices of the stepsize do not rely on the norm $\|A\|$.

In this paper, we first extend the above result for method (3) from nonexpansive mappings to demicontractive continuous mappings. By using properties of product spaces, we change the split equality problem into a special split common fixed point problem. As a result, based on our extension, we obtain a new method for solving the split equality problem in Hilbert spaces.

\section{Preliminaries}

Throughout the paper, $H_{i}, i=1,2,3$, are Hilbert spaces, $I$ is the identity operator, “ $\rightarrow$ " stands for strong convergence, and “ $\rightarrow$ " stands for weak convergence. For a mapping $W: H_{1} \rightarrow$ $H_{1}, F(W)$ is the set of the fixed points of $W, W^{-1}(0)=\{x \in$ $\left.H_{1}: W x=0\right\}$, and $W^{c}:=I-W$.

Definition 1. Let $W: H_{1} \rightarrow H_{1}$ be a nonlinear mapping.

(i) $W$ is called firmly nonexpansive, if

$$
\begin{aligned}
\|W x-W y\|^{2} \leq\|x-y\|^{2}-\left\|W^{c} x-W^{c} y\right\|^{2} & \\
& \\
& \forall x, y \in H_{1} .
\end{aligned}
$$

(ii) $W$ is called nonexpansive, if

$$
\|W x-W y\| \leq\|x-y\|, \quad \forall x, y \in H_{1} .
$$

(iii) $W$ is called strictly pseudo-contractive, if there exists $k<1$ such that

$$
\begin{array}{r}
\|W x-W y\|^{2} \leq\|x-y\|^{2}+k\left\|W^{c} x-W^{c} y\right\|^{2}, \\
\forall x, y \in H_{1} .
\end{array}
$$

(iv) $W$ is called $L$-Lipschitz continuous, if there exists $L>0$ such that

$$
\|W x-W y\| \leq L\|x-y\|, \quad \forall x, y \in H_{1} .
$$

Definition 2. Let $W: H_{1} \rightarrow H_{1}$ be a nonlinear mapping with $F(W) \neq \emptyset$.

(i) $W$ is called firmly quasi-nonexpansive, if

$$
\begin{aligned}
&\|W x-z\|^{2} \leq\|x-z\|^{2}-\|(I-W) x\|^{2}, \\
& \forall(x, z) \in H_{1} \times F(W) .
\end{aligned}
$$

(ii) $W$ is called quasi-nonexpansive, if

$$
\|W x-z\| \leq\|x-z\|, \quad \forall(x, z) \in H_{1} \times F(W) .
$$

(iii) $W$ is called $k$-demicontractive, if there exists $k<1$ such that

$$
\begin{aligned}
\|W x-z\|^{2} \leq\|x-z\|^{2}+k\|(I-W) x\|^{2} & \\
& \forall(x, z) \in H_{1} \times F(W) .
\end{aligned}
$$

Note that the class of strictly pseudo-contractive mappings properly includes the class of nonexpansive mappings, while the class of nonexpansive mappings properly includes the class of firmly nonexpansive mappings. And the class of demicontractive mappings properly includes the class of quasi-nonexpansive mappings, while the class of quasinonexpansive mappings properly includes the class of firmly quasi-nonexpansive mappings.

Definition 3 (demiclosedness property). Let $\left\{x_{n}\right\}$ be a sequence in $H_{1}$ and $W: H_{1} \rightarrow H_{1}$ be a mapping. Then $W$ is said to have demiclosedness property if the following implication holds:

$$
\left.\begin{array}{c}
(I-W) x_{n} \longrightarrow 0 \\
x_{n} \rightarrow x
\end{array}\right] \Longrightarrow x \in F(W) .
$$

It is known that strictly pseudo-contractive mappings possess the demiclosedness property [20]. In particular, both nonexpansive and firmly nonexpansive mappings possess such a property.

Lemma 4 (see [20]). Let $W: H_{1} \rightarrow H_{1}$ be a $k$-strictly pseudocontractive mapping. Then $W$ is demicontractive and Lipschitz continuous and moreover has the demiclosedness property.

The metric projection $P_{C}$ from $H_{1}$ onto a nonempty closed convex subset $C \subseteq H_{1}$ is defined by

$$
P_{C} x:=\underset{y \in C}{\operatorname{argmin}}\|x-y\|,
$$

which is characterized by

$$
\left\langle x-P_{C} x, z-P_{C} x\right\rangle \leq 0, \quad \forall z \in C .
$$

It is well known that the metric projection is firmly nonexpansive.

Definition 5. Let $C$ be a nonempty closed convex subset in $H_{1}$. 
(i) A sequence $\left\{x_{n}\right\}$ in $H_{1}$ is Fejér-monotone with respect to $C$ if

$$
\left\|x_{n+1}-z\right\| \leq\left\|x_{n}-z\right\|, \quad \forall n \geq 0, \forall z \in C .
$$

(ii) A sequence $\left\{x_{n}\right\}$ in $H_{1}$ is quasi Fejér-monotone with respect to $C$ if

$$
\left\|x_{n+1}-z\right\|^{2} \leq\left\|x_{n}-z\right\|^{2}+\varepsilon_{n}, \quad \forall n \geq 0, \forall z \in C,
$$

where $\left\{\varepsilon_{n}\right\} \subseteq(0,+\infty)$ satisfies $\sum_{n=1}^{\infty} \varepsilon_{n}<\infty$.

Lemma 6 (see [21]). A quasi Fejér-monotone sequence $\left\{x_{n}\right\}$ (with respect to $C$ ) is weakly convergent to $z \in C$ if and only if every weak cluster point of $\left\{x_{n}\right\}$ belongs to $C$.

Lemma 7 (see [22]). Let $\left\{\varepsilon_{n}\right\}$ and $\left\{s_{n}\right\}$ be positive real sequences such that $\sum_{n=0}^{\infty} \varepsilon_{n}<\infty$. If $s_{n+1} \leq\left(1+\varepsilon_{n}\right) s_{n}$, or $s_{n+1} \leq s_{n}+\varepsilon_{n}$, then the limit of the sequence $\left\{s_{n}\right\}$ exists.

\section{The Case for Demicontractive \\ Continuous Mappings}

In this section, we consider the SCFP (P1) for demicontractive continuous mappings. Under this situation, we shall prove that the sequence $\left\{x_{n}\right\}$ generated by (3) and (5)-(6) still converges weakly to a solution of problem (P1).

Lemma 8. Let $k_{1}, k_{2} \in(-\infty, 1), L_{1}, L_{2} \in(0,+\infty)$, and $W=(I-U)+A^{*}(I-T) A$, where $U, T$, and $A$ are mappings defined in (P1). Assume that $U$ is $k_{1}$-demicontractive and $L_{1}$ Lipschitz continuous, $T$ is $k_{2}$-demicontractive and $L_{2}$-Lipschitz continuous, and $I-U$ and $I-T$ are demiclosed at the origin. For any $(x, z) \in H_{1} \times S$, we have the following:

(i) $S=W^{-1}(0)$.

(ii) $2\langle W x, x-z\rangle \geq \min \left(\left(1-k_{1}\right) / 2,\left(1-k_{2}\right) / 2\|A\|^{2}\right)\|W x\|^{2}$.

(iii) $W$ is L-Lipschitz continuous with $L=\max \left(\left(L_{1}+\right.\right.$ 1), $\left.\left(L_{2}+1\right)\|A\|^{2}\right)$.

(iv) If $\left\|W x_{n}\right\| \rightarrow 0$ and $x_{n} \rightarrow x$ as $n \rightarrow \infty$, then $x \in S$.

Proof. (i) It is readily seen that $S \subseteq W^{-1}(0)$. To see the converse, let $x \in W^{-1}(0)$ and fix any $z \in S$. Since $U$ and $T$ are demicontractive, we have

$$
\begin{aligned}
\frac{1-k_{1}}{2}\|(I-U) x\|^{2} & \leq\langle(I-U) x, x-z\rangle, \\
\frac{1-k_{2}}{2}\|(I-T) A x\|^{2} & \leq\langle(I-T) A x, A x-A z\rangle .
\end{aligned}
$$

Adding up these two inequalities, we have

$$
\begin{aligned}
\langle W x, x-z\rangle \geq & \frac{1-k_{1}}{2}\|(I-U) x\|^{2} \\
& +\frac{1-k_{2}}{2}\|(I-T) A x\|^{2},
\end{aligned}
$$

which yields $\|(I-U) x\|=\|(I-T) A x\|=0$, that is, $x \in S$. This implies $S \supseteq W^{-1}(0)$. (ii) Let $(x, z) \in H_{1} \times S$. It follows from (20) that

$$
\begin{aligned}
& \langle W x, x-z\rangle \geq \frac{1-k_{1}}{2}\|(I-U) x\|^{2}+\frac{1-k_{2}}{2} \|(I-T) \\
& \cdot A x\left\|^{2}=\frac{1-k_{1}}{2}\right\|(I-U) x\left\|^{2}+\frac{1-k_{2}}{2\|A\|^{2}}\right\| A^{*} \|^{2} \\
& \cdot\|(I-T) A x\|^{2} \geq \frac{1-k_{1}}{2}\|(I-U) x\|^{2} \\
& +\frac{1-k_{2}}{2\|A\|^{2}}\left\|A^{*}(I-T) A x\right\|^{2} \\
& \geq \min \left(\frac{1-k_{1}}{2}, \frac{1-k_{2}}{2\|A\|^{2}}\right) \\
& \cdot\left(\|(I-U) x\|^{2}+\left\|A^{*}(I-T) A x\right\|^{2}\right) \\
& \geq \min \left(\frac{1-k_{1}}{4}, \frac{1-k_{2}}{4\|A\|^{2}}\right) \\
& \cdot\left\|\left((I-U)+A^{*}(I-T) A\right) x\right\|^{2},
\end{aligned}
$$

which yields the desired inequality.

(iii) Let $x, y \in H_{1}$. We have

$$
\begin{aligned}
& \|W x-W y\| \\
& \leq\|(I-U)(x-y)\|+\left\|A^{*}(I-T) A(x-y)\right\| \\
& \leq\left(L_{1}+1\right)\|x-y\|+\|A\|\|(I-T) A(x-y)\| \\
& \quad \leq\left(L_{1}+1\right)\|x-y\|+\left(L_{2}+1\right)\|A\|^{2}\|x-y\| \\
& \quad \leq \max \left(\left(L_{1}+1\right),\left(L_{2}+1\right)\|A\|^{2}\right)\|x-y\| .
\end{aligned}
$$

(iv) We note that $\left\{x_{n}\right\}$ is bounded by its weak convergence. By inequality (20), we have

$$
\begin{gathered}
\frac{1-k_{1}}{2}\left\|(I-U) x_{n}\right\|^{2}+\frac{1-k_{2}}{2}\left\|(I-T) A x_{n}\right\|^{2} \\
\leq\left\langle W x_{n}, x_{n}-z\right\rangle \leq\left\|W x_{n}\right\|\left\|x_{n}-z\right\| \longrightarrow
\end{gathered}
$$

0 ,

which implies that

$$
\lim _{n \rightarrow \infty}\left\|(I-U) x_{n}\right\|=\lim _{n \rightarrow \infty}\left\|(I-T) A x_{n}\right\|=0 .
$$

Since $x_{n} \rightarrow x$, this by the demiclosedness property implies $x \in F(U)$. On the other hand, for any $y \in H_{2}$, we have

$$
\begin{aligned}
\lim _{n \rightarrow \infty}\left\langle A x_{n}, y\right\rangle & =\lim _{n \rightarrow \infty}\left\langle x_{n}, A^{*} y\right\rangle=\left\langle x, A^{*} y\right\rangle \\
& =\langle A x, y\rangle .
\end{aligned}
$$

Hence $A x_{n} \rightarrow A x$, which yields $A x \in F(T)$. Altogether, $x \in$ $S$. 
Theorem 9. Let $k_{1}, k_{2} \in(-\infty, 1), L_{1}, L_{2} \in(0,+\infty)$. Assume that $U$ is $k_{1}$-demicontractive and $L_{1}$-Lipschitz continuous, $T$ is $k_{2}$-demicontractive and $L_{2}$-Lipschitz continuous, and $I-U$ and $I-T$ are demiclosed at the origin. If condition (6) holds, then the sequence $\left\{x_{n}\right\}$, generated by (3) and (5), converges weakly to a solution of problem (P1).

Proof. Let $z \in S, \tau=\min \left(\left(1-k_{1}\right) / 2,\left(1-k_{2}\right) / 2\|A\|^{2}\right)$, and $L=\max \left(\left(L_{1}+1\right),\left(L_{2}+1\right)\|A\|^{2}\right)$. It then follows from Lemma 8 that

$$
\begin{aligned}
\left\|x_{n+1}-z\right\|^{2}= & \left\|x_{n}-z\right\|^{2}-2 \rho_{n}\left\langle W x_{n}, x_{n}-z\right\rangle \\
& +\rho_{n}^{2}\left\|W x_{n}\right\|^{2} \\
\leq & \left\|x_{n}-z\right\|^{2}-\tau \rho_{n}\left\|W x_{n}\right\|^{2}+\rho_{n}^{2}\left\|W x_{n}\right\|^{2} .
\end{aligned}
$$

By (5), we have

$$
\left\|x_{n+1}-z\right\|^{2} \leq\left\|x_{n}-z\right\|^{2}-\tau \tau_{n}\left\|W x_{n}\right\|+\tau_{n}^{2} ;
$$

in particular,

$$
\left\|x_{n+1}-z\right\|^{2} \leq\left\|x_{n}-z\right\|^{2}+\tau_{n}^{2} .
$$

By our hypothesis (6), this implies that $\left\{x_{n}\right\}$ is quasi Fejérmonotone with respect to $S$.

Next, we deduce from (27) and the boundedness of $\left\{x_{n}\right\}$ (guaranteed by the quasi-Fejér-monotonicity) that

$$
\tau_{n}\left\|W x_{n}\right\| \leq \frac{1}{\tau}\left(\left\|x_{n}-z\right\|^{2}-\left\|x_{n+1}-z\right\|^{2}+\tau_{n}^{2}\right) .
$$

Thus, we have

$$
\sum_{n=0}^{\infty} \tau_{n}\left\|W x_{n}\right\|<\infty
$$

In view of (6), this implies

$$
\varliminf_{n \rightarrow \infty}\left\|W x_{n}\right\|=0
$$

On the other hand, since

$$
\left\|W x_{n+1}-W x_{n}\right\| \leq L\left\|x_{n}-x_{n+1}\right\|=L \rho_{n}\left\|W x_{n}\right\|,
$$

then we have

$$
\begin{aligned}
\left\|W x_{n+1}\right\|^{2}= & \left\|W x_{n}\right\|^{2}+\left\|W x_{n+1}-W x_{n}\right\|^{2} \\
& +2\left\langle W x_{n}, W x_{n+1}-W x_{n}\right\rangle \\
\leq & \left\|W x_{n}\right\|^{2}+\left\|W x_{n+1}-W x_{n}\right\|^{2} \\
& +2\left\|W x_{n}\right\|\left\|W x_{n+1}-W x_{n}\right\| \\
\leq & \left\|W x_{n}\right\|^{2}+L^{2} \rho_{n}^{2}\left\|W x_{n}\right\|^{2}+2 L \rho_{n}\left\|W x_{n}\right\|^{2} \\
= & \left\|W x_{n}\right\|^{2}+L^{2} \tau_{n}^{2}+2 L \tau_{n}\left\|W x_{n}\right\| .
\end{aligned}
$$

In light of (30) and (6), we have $\sum_{n}\left(L^{2} \tau_{n}^{2}+2 L \tau_{n}\left\|W x_{n}\right\|\right)<$ $\infty$. By Lemma $7, \lim _{n}\left\|W x_{n}\right\|$ exists, and further we have $\lim _{n}\left\|W x_{n}\right\|=0$ by (31). Hence, by Lemma 8 , we conclude that every weak cluster point of $\left\{x_{n}\right\}$ belongs to $S$.

Finally, we deduce from Lemma 6 that $\left\{x_{n}\right\}$ converges weakly to a solution of problem (P1).

Corollary 10. Assume that $U$ and $T$ are both strictly pseudocontractive mappings. If condition (6) holds, then the sequence $\left\{x_{n}\right\}$, generated by (3) and (5), converges weakly to a solution of problem (P1).

Proof. It follows from Lemma 4 and Theorem 9.

Remark 11. It is readily seen that the above result holds true for nonexpansive and firmly nonexpansive mappings. As a result, it extends the results in [19] from nonexpansive mappings to demicontractive continuous mappings.

\section{New Methods for the Split Equality Problem}

The split equality problem (SEP) is an inverse problem that requests finding

$$
(x, y) \in F\left(U_{1}\right) \times F\left(U_{2}\right) \text { s.t. } A_{1} x=A_{2} y,
$$

where $A_{1}: H_{1} \rightarrow H_{3}$ and $A_{2}: H_{2} \rightarrow H_{3}$ are two bounded linear mappings, while $U_{1}: H_{1} \rightarrow H_{1}$ and $U_{2}: H_{2} \rightarrow H_{2}$ are two nonlinear mappings. The SEP was first introduced by Moudafi and Al-Shemas [23], and they proposed the following iterative method:

$$
\begin{aligned}
& x_{n+1}=U_{1}\left[x_{n}-\tau_{n} A^{*}\left(A x_{n}-B y_{n}\right)\right], \\
& y_{n+1}=U_{2}\left[y_{n}+\tau_{n} B^{*}\left(A x_{n}-B y_{n}\right)\right] .
\end{aligned}
$$

Under some certain conditions, they proved the weak convergence of the iterative sequence generated by method (34).

Our method is actually motivated by (3), since problem (P2) can be regarded as a special SCFP: find $\mathbf{x}=\left(x_{1}, x_{2}\right) \epsilon$ $H_{1} \times H_{2}$ such that

$$
\mathbf{x} \in F(\mathbf{U})
$$

$$
\mathbf{A x} \in F(\mathbf{T})
$$

where $\mathbf{U x}=\left(U_{1} x_{1}, U_{2} x_{2}\right), \mathbf{A x}=A_{1} x_{1}-A_{2} x_{2}$, and $\mathbf{T}$ is the projection onto the set $\{0\}$. Motivated by (3), we now propose a new method for solving problem (P2). For an arbitrary initial guess $\left(x_{0}, y_{0}\right)$, define $\left(x_{n}, y_{n}\right)$ recursively by

$$
\begin{aligned}
& x_{n+1}=x_{n}-\rho_{n}\left[\left(I-U_{1}\right) x_{n}+A_{1}^{*}\left(A_{1} x_{n}-A_{2} y_{n}\right)\right], \\
& y_{n+1}=y_{n}-\rho_{n}\left[\left(I-U_{2}\right) y_{n}-A_{2}^{*}\left(A_{1} x_{n}-A_{2} y_{n}\right)\right],
\end{aligned}
$$

where $\left\{\rho_{n}\right\}$ is chosen as 


$$
\rho_{n}=\frac{\tau_{n}}{\left(\left\|\left(I-U_{1}\right) x_{n}+A_{1}^{*}\left(A_{1} x_{n}-A_{2} y_{n}\right)\right\|^{2}+\left\|\left(I-U_{2}\right) y_{n}-A_{2}^{*}\left(A_{1} x_{n}-A_{2} y_{n}\right)\right\|^{2}\right)^{1 / 2}} .
$$

In what follows, we will show the SEP amounts to problem (35). Now consider the product space $H_{1} \times H_{2}$, in which the inner product and the norm are, respectively, defined by

$$
\begin{aligned}
\langle\mathbf{x}, \mathbf{y}\rangle & =\left\langle x_{1}, y_{1}\right\rangle+\left\langle x_{2}, y_{2}\right\rangle, \\
\|\mathbf{x}\| & =\left(\left\|x_{1}\right\|^{2}+\left\|x_{2}\right\|^{2}\right)^{1 / 2},
\end{aligned}
$$

where $\mathbf{x}=\left(x_{1}, x_{2}\right), \mathbf{y}=\left(y_{1}, y_{2}\right)$ with $x_{1}, y_{1} \in H_{1}, x_{2}, y_{2} \in H_{2}$.

Lemma 12. Let $x_{1} \in H_{1}, x_{2} \in H_{2}$, and $A_{1}: H_{1} \rightarrow H_{3}$ and $A_{2}: H_{2} \rightarrow H_{3}$ be as in problem (P2). Define a mapping A : $H_{1} \times H_{2} \rightarrow H_{3}$ by

$$
\mathbf{A x}=\mathbf{A}\left(x_{1}, x_{2}\right)=A_{1} x_{1}-A_{2} x_{2} .
$$

Then we have the following:

(i) A is a bounded linear mapping.

(ii) $\mathbf{A}^{*} \mathbf{A} \mathbf{x}=\left(A_{1}^{*}\left(A_{1} x_{1}-A_{2} x_{2}\right),-A_{2}^{*}\left(A_{1} x_{1}-A_{2} x_{2}\right)\right)$.

Proof. (i) Let $\alpha, \beta \in \mathbb{R}$. Since $A_{1}$ and $A_{2}$ are both linear, we have

$$
\begin{aligned}
\mathbf{A}(\alpha \mathbf{x}+\beta \mathbf{y}) & =\mathbf{A}\left(\alpha\left(x_{1}, x_{2}\right)+\beta\left(y_{1}, y_{2}\right)\right) \\
& =\mathbf{A}\left(\left(\alpha x_{1}+\beta y_{1}\right),\left(\alpha x_{2}+\beta y_{2}\right)\right) \\
& =A_{1}\left(\alpha x_{1}+\beta y_{1}\right)-A_{2}\left(\alpha x_{2}+\beta y_{2}\right) \\
& =\alpha\left(A_{1} x_{1}-A_{2} x_{2}\right)+\beta\left(A_{1} y_{1}-A_{2} y_{2}\right) \\
& =\alpha \mathbf{A}\left(x_{1}, x_{2}\right)+\beta \mathbf{A}\left(y_{1}, y_{2}\right) \\
& =\alpha \mathbf{A} \mathbf{x}+\beta \mathbf{A y} ;
\end{aligned}
$$

on the other hand, we have

$$
\begin{aligned}
\|\mathbf{A x}\| & =\left\|A_{1} x_{1}-A_{2} x_{2}\right\| \leq\left\|A_{1}\right\|\left\|x_{1}\right\|+\left\|A_{2}\right\|\left\|x_{2}\right\| \\
& \leq \max \left(\left\|A_{1}\right\|,\left\|A_{2}\right\|\right)\left(\left\|x_{1}\right\|+\left\|x_{2}\right\|\right) \\
& \leq \sqrt{2} \max \left(\left\|A_{1}\right\|,\left\|A_{2}\right\|\right) \sqrt{\left\|x_{1}\right\|^{2}+\left\|x_{2}\right\|^{2}} \\
& =\sqrt{2} \max \left(\left\|A_{1}\right\|,\left\|A_{2}\right\|\right)\|\mathbf{x}\|,
\end{aligned}
$$

which implies $\|\mathbf{A}\| \leq \sqrt{2} \max \left(\left\|A_{1}\right\|,\left\|A_{2}\right\|\right)$. Thus $\mathbf{A}$ is linear and bounded.

(ii) For $w \in H_{3}$, we have

$$
\begin{aligned}
\langle\mathbf{A} \mathbf{x}, w\rangle & =\left\langle\mathbf{A}\left(x_{1}, x_{2}\right), w\right\rangle=\left\langle A_{1} x_{1}-A_{2} x_{2}, w\right\rangle \\
& =\left\langle x_{1}, A_{1}^{*} w\right\rangle+\left\langle x_{2},-A_{2}^{*} w\right\rangle \\
& =\left\langle\left(x_{1}, x_{2}\right),\left(A_{1}^{*} w,-A_{2}^{*} w\right)\right\rangle \\
& =\left\langle\mathbf{x},\left(A_{1}^{*} w,-A_{2}^{*} w\right)\right\rangle .
\end{aligned}
$$

This gives $\mathbf{A}^{*} w=\left(A_{1}^{*} w,-A_{2}^{*} w\right)$, which implies that

$$
\begin{aligned}
\mathbf{A}^{*} \mathbf{A} \mathbf{x} & =\mathbf{A}^{*}\left(A_{1} x_{1}-A_{2} x_{2}\right) \\
& =\left(A_{1}^{*}\left(A_{1} x_{1}-A_{2} x_{2}\right),-A_{2}^{*}\left(A_{1} x_{1}-A_{2} x_{2}\right)\right) .
\end{aligned}
$$

Hence the lemma is proved.

Lemma 13. Assume that $U_{1}: H_{1} \rightarrow H_{1}$ is $k_{1}$-demicontractive and $L_{1}$-Lipschitz continuous, $U_{2}: H_{2} \rightarrow H_{2}$ is $k_{2}$ demicontractive and $L_{2}$-Lipschitz continuous, and $I-U_{1}$ and $I-U_{2}$ are demiclosed at the origin. Define a mapping $\mathbf{U}$ : $H_{1} \times H_{2} \rightarrow H_{1} \times H_{2}$ by

$$
\mathbf{U} \mathbf{x}=\left(U_{1} x_{1}, U_{2} x_{2}\right),
$$

where $\mathbf{x}=\left(x_{1}, x_{2}\right)$ is in $H_{1} \times H_{2}$ with $x_{1} \in H_{1}, x_{2} \in H_{2}$. Then

(i) $F(\mathbf{U})=F\left(U_{1}\right) \times F\left(U_{2}\right)$;

(ii) $\mathrm{U}$ is demicontractive and Lipschitz continuous;

(iii) $\mathbf{I}-\mathbf{U}$ is demiclosed at the origin.

Proof. It is easy to check (i). For (ii), fix $z=\left(z_{1}, z_{2}\right) \in F(\mathbf{U})$. It follows that

$$
\begin{aligned}
& \|\mathbf{U} \mathbf{x}-\mathbf{z}\|^{2}=\left\|U_{1} x_{1}-z_{1}\right\|^{2}+\left\|U_{2} x_{2}-z_{2}\right\|^{2} \\
& =\left\|x_{1}-z_{1}\right\|^{2}+\left\|x_{2}-z_{2}\right\|^{2}+k_{1}\left\|U_{1} x_{1}-x_{1}\right\|^{2} \\
& \quad+k_{2}\left\|U_{2} x_{2}-x_{2}\right\|^{2} \\
& \leq\left\|x_{1}-z_{1}\right\|^{2}+\left\|x_{2}-z_{2}\right\|^{2} \\
& \quad+\max \left(k_{1}, k_{2}\right)\left(\left\|U_{1} x_{1}-x_{1}\right\|^{2}+\left\|U_{2} x_{2}-x_{2}\right\|^{2}\right) \\
& =\left\|\left(x_{1}, x_{2}\right)-\left(z_{1}, z_{2}\right)\right\|^{2} \\
& \quad+\max \left(k_{1}, k_{2}\right)\left\|(\mathbf{I}-\mathbf{U})\left(x_{1}, x_{2}\right)\right\|^{2} \\
& =\|\mathbf{x}-\mathbf{z}\|^{2}+\max \left(k_{1}, k_{2}\right)\|(\mathbf{I}-\mathbf{U}) \mathbf{x}\|^{2},
\end{aligned}
$$

which implies that $\mathbf{U}$ is demicontractive. On the other hand, we have

$$
\begin{aligned}
& \|\mathbf{U} \mathbf{x}-\mathbf{U} \mathbf{y}\|=\left\|\left(U_{1} x_{1}-U_{1} y_{1}, U_{2} x_{2}-U_{2} y_{2}\right)\right\| \\
& =\left(\left\|U_{1} x_{1}-U_{1} y_{1}\right\|^{2}+\left\|U_{2} x_{2}-U_{2} y_{2}\right\|^{2}\right)^{1 / 2} \\
& \leq\left(L_{1}^{2}\left\|x_{1}-y_{1}\right\|^{2}+L_{2}^{2}\left\|x_{2}-y_{2}\right\|^{2}\right)^{1 / 2} \\
& \leq \max \left(L_{1}, L_{2}\right)\left(\left\|x_{1}-y_{1}\right\|^{2}+\left\|x_{2}-y_{2}\right\|^{2}\right)^{1 / 2} \\
& =\max \left(L_{1}, L_{2}\right)\left\|\left(x_{1}, y_{1}\right)-\left(x_{2}, y_{1}\right)\right\| \\
& =\max \left(L_{1}, L_{2}\right)\|\mathbf{x}-\mathbf{y}\|,
\end{aligned}
$$


where $\mathbf{y}=\left(y_{1}, y_{2}\right)$ is in $H_{1} \times H_{2}$ with $y_{1} \in H_{1}, y_{2} \in H_{2}$. This implies that $\mathbf{U}$ is Lipschitz continuous.

To show (iii), let $\left\{\left(x_{n}, y_{n}\right)\right\}$ be a sequence such that it converges weakly to $\{(x, y)\}$ and $(\mathbf{I}-\mathbf{U})\left(x_{n}, y_{n}\right)$ converges strongly to 0 . This implies that $x_{n} \rightarrow x$ and $\left(I-U_{1}\right) x_{n} \rightarrow 0$, which, by the demiclosedness of $I-U_{1}$, gives $x \in F\left(U_{1}\right)$. Similarly, we have $y \in F\left(U_{2}\right)$, so that $(x, y) \in F\left(U_{1}\right) \times F\left(U_{2}\right)=$ $F(\mathbf{U})$. So the lemma is proved.

Theorem 14. Assume that $U_{1}: H_{1} \rightarrow H_{1}$ and $U_{2}: H_{2} \rightarrow H_{2}$ are two demicontractive and Lipschitz continuous mappings such that $I-U_{1}$ and $I-U_{2}$ are demiclosed at the origin. If condition (6) is fulfilled, then the sequence $\left\{\left(x_{n}, y_{n}\right)\right\}$ generated by (36), (37), and (48) converges weakly to a solution of problem (P2).

Proof. Let $\mathbf{z}_{n}=\left(x_{n}, y_{n}\right), \mathbf{U}, \mathbf{A}$ be defined as in the previous lemmas, and $\mathbf{T}$ be the projection onto the set $\{0\}$. Then method (36) can be rewritten as

$$
\mathbf{z}_{n+1}=\mathbf{z}_{n}-\rho_{n}\left[(\mathbf{I}-\mathbf{U}) \mathbf{z}_{n}+\mathbf{A}^{*}(\mathbf{I}-\mathbf{T}) \mathbf{A} \mathbf{z}_{n}\right],
$$

where

$$
\rho_{n}=\frac{\tau_{n}}{\left\|(\mathbf{I}-\mathbf{U}) \mathbf{z}_{n}+\mathbf{A}^{*}(\mathbf{I}-\mathbf{T}) \mathbf{A} \mathbf{z}_{n}\right\|} .
$$

Note that $\mathbf{T}$ is firmly nonexpansive. By Lemma 13, all assumptions in Theorem 9 are fulfilled. Hence, by applying Theorem 9, we conclude that $\left\{\mathbf{z}_{n}\right\}$ converges weakly to some $\mathbf{z}=(x, y)$ such that $\mathbf{z} \in F(\mathbf{U})=F\left(U_{1}\right) \times F\left(U_{2}\right)$ and $\mathbf{A z} \in$ $F(\mathbf{T})=\{0\}$, which clearly yields $x \in F\left(U_{1}\right), y \in F\left(U_{2}\right)$, and $A_{1} x=A_{2} y$. Hence the theorem is proved.

\section{Conclusions}

We studied the split common fixed point problem in Hilbert spaces. We proposed a new method for solving such a problem and established a weak convergence theorem whenever the involved mappings are demicontractive and continuous. We also obtained a new method for solving the split equality problem in Hilbert spaces.

\section{Conflicts of Interest}

The authors declare that they have no conflicts of interest.

\section{Acknowledgments}

This work was supported by Program for Science and Technology Innovation Talents in the Universities of Henan Province (Grant no. 15HASTIT013).

\section{References}

[1] C. Byrne, "Iterative oblique projection onto convex sets and the split feasibility problem," Inverse Problems, vol. 18, no. 2, pp. 441453, 2002.

[2] C. Byrne, "A unified treatment of some iterative algorithms in signal processing and image reconstruction," Inverse Problems, vol. 20, no. 1, pp. 103-120, 2004.
[3] Y. Censor, T. Bortfeld, B. Martin, and A. Trofimov, "A unified approach for inversion problems in intensity-modulated radiation therapy," Physics in Medicine and Biology, vol. 51, no. 10, pp. 2353-2365, 2006.

[4] E. Masad and S. Reich, "A note on the multiple-set split convex feasibility problem in Hilbert space," Journal of Nonlinear and Convex Analysis, vol. 8, no. 3, pp. 367-371, 2007.

[5] H.-K. Xu, "Properties and iterative methods for the lasso and its variants," Chinese Annals of Mathematics, Series B, vol. 35, no. 3, pp. 501-518, 2014.

[6] Y. Censor and A. Segal, "The split common fixed point problem for directed operators," Journal of Convex Analysis, vol. 16, no. 2, pp. 587-600, 2009.

[7] A. Moudafi, "A note on the split common fixed-point problem for quasi-nonexpansive operators," Nonlinear Analysis, vol. 74, no. 12 , pp. 4083-4087, 2011.

[8] H. Cui and F. Wang, "Iterative methods for the split common fixed point problem in Hilbert spaces," Fixed Point Theory and Applications, vol. 1, pp. 1-8, 2014.

[9] A. Moudafi, "The split common fixed-point problem for demicontractive mappings," Inverse Problems, vol. 26, no. 5, Article ID 055007, p. 6, 2010.

[10] A. Cegielski, "General method for solving the split common fixed point problem," Journal of Optimization Theory and Applications, vol. 165, no. 2, pp. 385-404, 2015.

[11] F. Wang and H.-K. Xu, "Cyclic algorithms for split feasibility problems in Hilbert spaces," Nonlinear Analysis, vol. 74, no. 12, pp. 4105-4111, 2011.

[12] C. Byrne, Y. Censor, A. Gibali, and S. Reich, "The split common null point problem," Journal of Nonlinear and Convex Analysis, vol. 13, no. 4, pp. 759-775, 2012.

[13] O. A. Boikanyo, "A strongly convergent algorithm for the split common fixed point problem," Applied Mathematics and Computation, vol. 265, Article ID 21251, pp. 844-853, 2015.

[14] R. Kraikaew and S. Saejung, "On split common fixed point problems," Journal of Mathematical Analysis and Applications, vol. 415, no. 2, pp. 513-524, 2014.

[15] C. Zhang and Z. Xu, "Explicit iterativ algorithm for solving split variational inculsion and fixed point problem for the infinite family of noexpansive operators," Nonlinear Functional Analysis and Applications, vol. 21, pp. 669-683, 2016.

[16] J. Zhao and S. Wang, "Viscosity approximation methods for the split common fixed point problem of quasi-strict pseudocontractions without prior knowledge of operator norms," Nonlinear Functional Analysis and Applications, vol. 20, pp. 199213, 2015.

[17] G. López, V. Martín, F. Wang, and H.-K. Xu, "Solving the split feasibility problem without prior knowledge of matrix norms," Inverse Problems, vol. 28, no. 8, Article ID 085004, 085004, 18 pages, 2012.

[18] F. Wang, "A new method for split common fixed-point problem without priori knowledge of operator norms," Journal of Fixed Point Theory and Applications, vol. 19, no. 4, pp. 2427-2436, 2017.

[19] F. Wang and H. K. Xu, Weak and Strong Convergence of Two Algorithms for the Split Fixed Point Problem, to Appear in Numerical Mathematics: Theory, Methods, and Applications.

[20] G. Marino and H.-K. Xu, "Weak and strong convergence theorems for strict pseudo-contractions in Hilbert spaces," Journal of Mathematical Analysis and Applications, vol. 329, no. 1, pp. 336-346, 2007. 
[21] P. L. Combettes, "Quasi-Fejérian analysis of some optimization algorithms," in Inherently Parallel Algorithms in Feasibility and Optimization and Their Applications, vol. 8 of Studies in Computational Mathematics, pp. 115-152, North-Holland, Amsterdam, 2001.

[22] K.-K. Tan and H. K. Xu, "Approximating fixed points of nonexpansive mappings by the Ishikawa iteration process," Journal of Mathematical Analysis and Applications, vol. 178, no. 2, pp. 301-308, 1993.

[23] A. Moudafi and E. Al-Shemas, "Simultaneous iterative methods for split equality problems and application," Transactions on Mathematical Programming and Applications, vol. 1, pp. 1-11, 2013. 


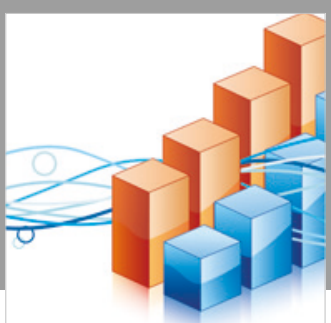

Advances in

Operations Research

\section{-n-m}
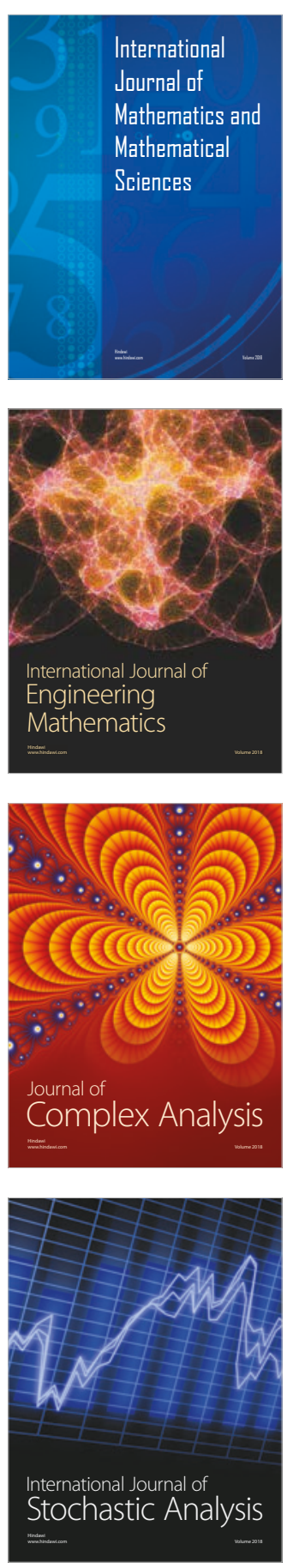
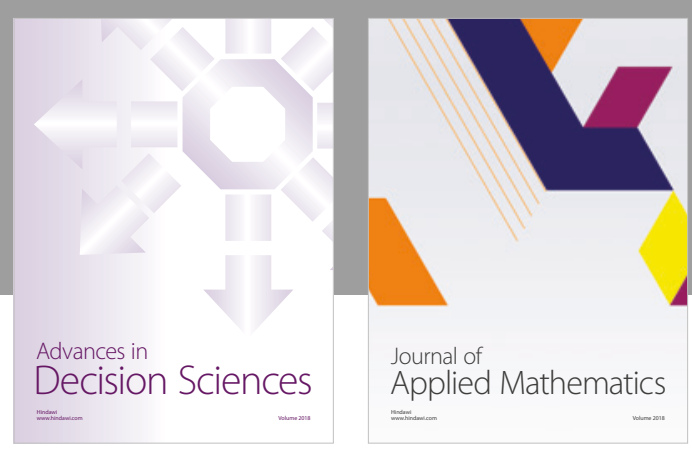

Journal of

Applied Mathematics
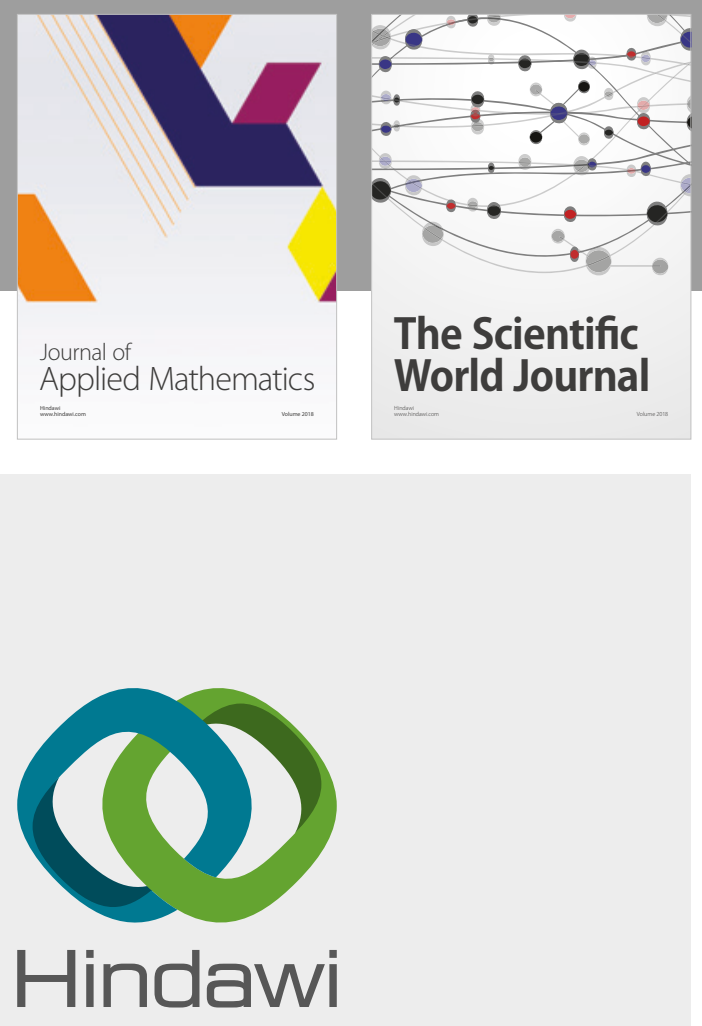

Submit your manuscripts at

www.hindawi.com

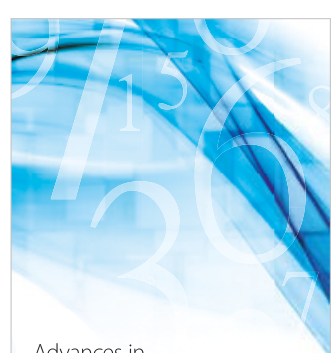

Advances in
Numerical Analysis
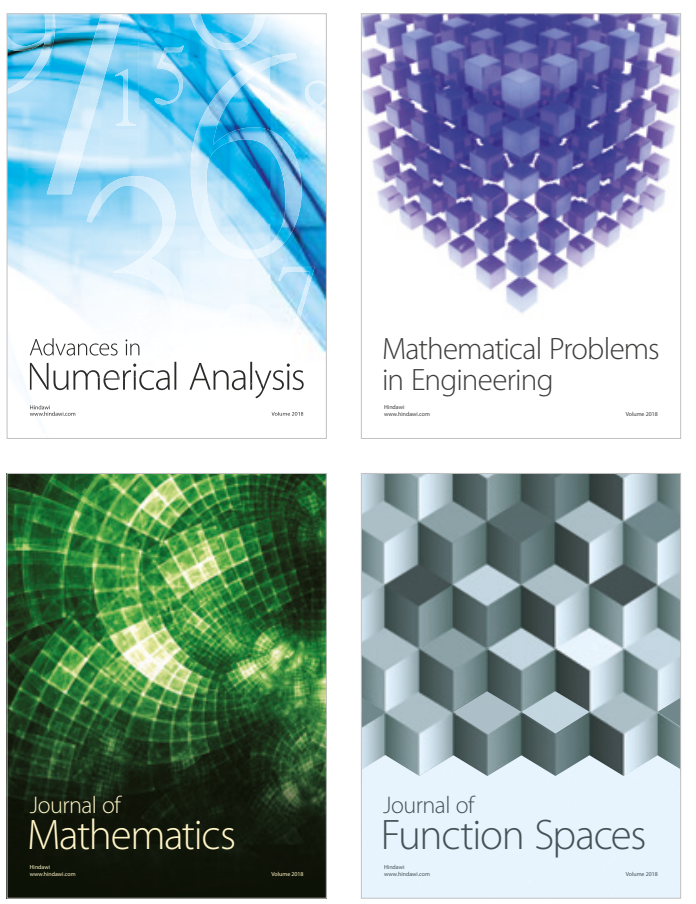

Mathematical Problems in Engineering

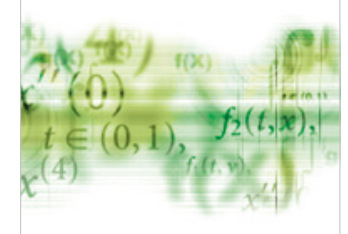

International Journal of

Differential Equations

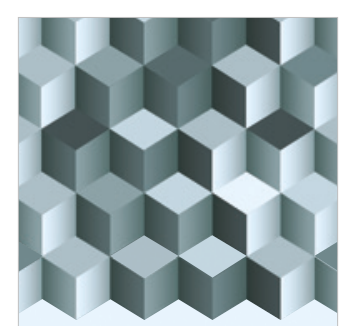

Journal of

Function Spaces

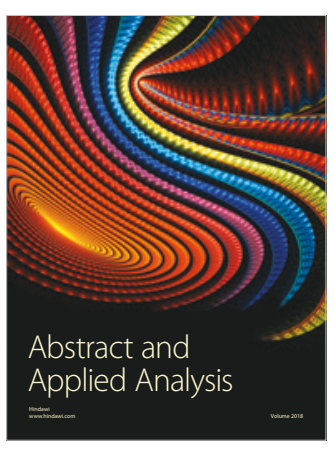

The Scientific

World Journal

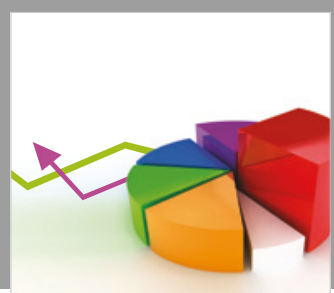

Journal of

Probability and Statistics
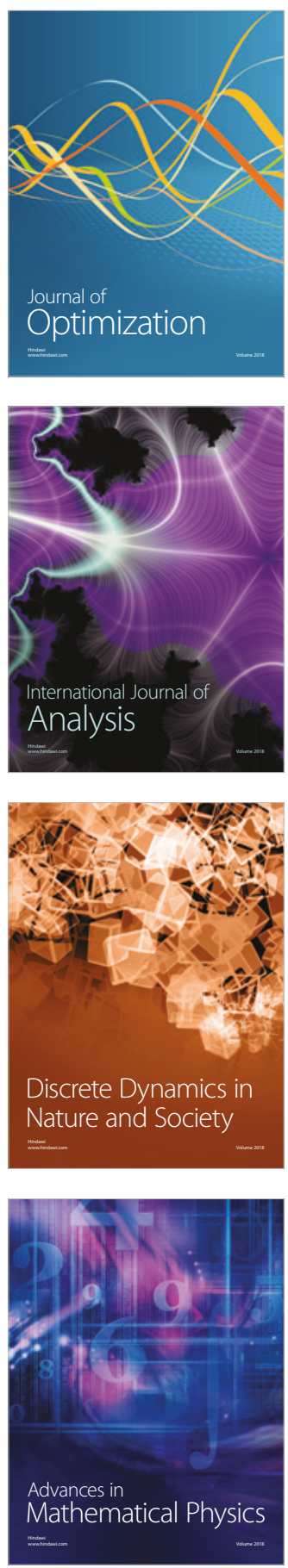